\title{
Numerical Treatment for the Three-Dimensional Eyring-Powell Fluid Flow over a Stretching Sheet with Velocity Slip and Activation Energy
}

\author{
Muhammad Umar, ${ }^{1,2}$ Rizwan Akhtar ${ }^{D},{ }^{1}$ Zulqurnain Sabir, ${ }^{2}$ Hafiz Abdul Wahab $(D)$, \\ Zhu Zhiyu, ${ }^{1}$ Ali Imran, ${ }^{3}$ Muhammad Shoaib, ${ }^{3}$ and Muhammad Asif Zahoor Raja $\mathbb{D}^{4}$ \\ ${ }^{1}$ School of Electronics and Information, Jiangsu University of Science and Technology, Zhenjiang, China \\ ${ }^{2}$ Department of Mathematics and Statistics, Hazara University, Mansehra, Pakistan \\ ${ }^{3}$ Department of Mathematics, COMSATS University Islamabad, Attock Campus, Attock, Pakistan \\ ${ }^{4}$ Department of Electrical and Computer Engineering, COMSATS University Islamabad, Attock Campus, Attock, Pakistan
}

Correspondence should be addressed to Rizwan Akhtar; rizwan@just.edu.cn

Received 13 March 2019; Accepted 18 April 2019; Published 6 May 2019

Academic Editor: Ivan Giorgio

Copyright (C) 2019 Muhammad Umar et al. This is an open access article distributed under the Creative Commons Attribution License, which permits unrestricted use, distribution, and reproduction in any medium, provided the original work is properly cited.

In this manuscript, a computational paradigm of technique shooting is exploited for investigation of the three-dimensional EyringPowell fluid with activation energy over a stretching sheet with slip arising in the field of fluid dynamics. The problem is modeled and resulting nonlinear system of PDEs is transformed into nonlinear system of ODEs using well-known similarity transformations. The strength of shooting based computing approach is employed to analyze the dynamics of the system. The proposed technique is well-designed for different scenarios of the system based on three-dimensional non-Newtonian fluid with activation energy over a stretching sheet. Slip condition is also incorporated to enhance the physical and dynamical analysis of the system. The proposed results are compared with the bvp4C method for the correctness of the solver. Graphical and numerical illustrations are used to envisage the behavior of different proficient physical parameters of interest including magnetic parameter, stretching rate parameter, velocity slip parameter, Biot number on velocity, and Lewis number on temperature and concentration.

\section{Introduction}

From the last few decades, considering the non-Newtonian nature of different physiological fluid and their use in the industry, researchers are paying their attention in the fluid mechanics field on non-Newtonian fluid models. Examples of this category of fluids are Reiner-Philippoff fluid, Casson fluid, micropolar fluid, Prandtl-Eyring fluid, Carreau fluid, power law fluid, Prandtl fluid, and Eyring-Powell fluid. Powell et al. [1] witnessed that, at moderate stresses, the fluid velocity is exponentially dependent on the stress, but as the stress level is enhanced, velocity behaves linearly in the flow. Patel et al. [2] reported that the Eyring-Powell model is useful and has significant benefits in comparison with the power law model. Fluid flow close to a dynamic plate for the Eyring-Powell with the help of three different techniques has been studied by Sirohi et al. [3]. Considering the complexity of the fluid time scale with the aid of Powell-Eyring fluid model, the impact of the very small and large shear rate viscosities is reported by Yoon et al. [4]. Nadeem et al. [5] explained the peristaltic flow by using Eyring-Powell fluid in their study. They concluded that, by enhancing the nonNewtonian Eyring-Powell flow parameter, increase in the peristaltic pumping region is observed. Time independent flow of incompressible boundary layer flow of Eyring-Powell nanofluid past shrinking sheet has been investigated by Motsa et al. [6]. Jayachandra et al. [7] and later Hayat et al. [8] analyzed the double stratification effects using Eyring-Powell.

The field of nanotechnology has gotten much attention among the engineers and scientists due to its vast applications in industrial and medical sciences like ceramics and drug delivery, etc. Nanofluids are modeled because of the 
suspension of nanoshaped elements in the base liquid. Most commonly used nanoparticles are $\mathrm{Al}, \mathrm{Ti}, \mathrm{Ag}, \mathrm{Cu}$, and their oxides. The nanofluid flow passing through stretching sheet near stagnation point was analyzed by Mustafa et al. [9]. Makinde et al. [10] analyzed nonisothermal boundary layer nanofluid fluid because of linear stretching surface. Sheikholeslami et al. [11] reported the heat transfer properties for nanofluid flow in the channel. Goodarzi et al. [12] reported nanofluids flow for laminar and turbulent case in a channel of narrow cavity, by using two types mixture model. Malvandi et al. [13] presented the flow for multiple convection nanofluid underneath the transverse narrow channel by using modified Buongiorno's model. Kuznetsov et al. [14] reported natural convection nanofluid flow past a vertical plate. The $3 \mathrm{D}$ flow of second grade nanofluid was analyzed by Hayat et al. [15]; they used an exponentially stretching surface and studied the flow due to the thermal radiation effect and heat source/sink. Hedayati et al. [16] analyzed the convection enforced nanofluid flow in a narrow channels using asymmetrically provided heat. Using the heat source/sink, three-dimensional Maxwell nanofluid boundary layer flow was studied by Hayat et al. [17]. Ellahi et al. [18] discussed entropy induced nanofluid flow using the behaviors of nanoparticles geometry. Latiff et al. [19] reported the bioconvection boundary layer micropolar nanofluid flow over a variable size sheet using diverse slip impacts. Uddin et al. [20] analyzed bioconvection nanofluid flow past a dynamic plate using the variations of Stefan injection along with diverse slip.

Several models for the slip at the boundary flow have been investigated in the span of previous few decades. Some intensively employed models are Maxwell's boundary-slip flow model of order first [21], slip boundary flow model of second order [22], Fukui-Kaneko (FK) slip boundary flow model [23], and slip boundary flow model of fractional order [24]. All of these models have been originated with the help of kinetic theory for gases. The Fukui-Kaneko slip model is adequately precise; however, it very much relies on the shape of the flow and dependent upon the flow parameters involved. These velocity slip models of first grade, second grade, and fractional grade work well when the Kundsen number is taken between zero and one. The aforementioned models are extensively being employed in science and engineering problems. Currently, Lin Wu [25] studied enhanced slip model of second grade that is considered accurate and reliable in comparison with the FK model. This model is considered superior over previous slip models, because of its applicability for all Kundsen number. For more insightful understanding of the flow behaviors, several researchers worked on Wu's model using various physical parameters. Furthermore, Ibrahim and Shankar [26] introduced the slips of three types: velocity, solutes, and thermal, due to flow of MHD nanofluid through a stretching sheet.

Zhang et al. [27] developed a new scheme to optimize the GRNN parameter and also introduced a new nonlinear function fitting scheme. Duan et al. [28] presented incompressible SPH algorithm by soothing the constant invariant density scenario for fluid of constant density. Qing et al. [29] by using finite volume technique explored the impacts of water entry angle through cavitation flow region.

The activation energy is the least required energy that reactants have to obtain, so that a chemical reaction can be anticipated. The phenomenon of mass transfer happens because of concentration variance of types in a mixture. The types that can vary the concentration in a mixture flow from large concentration section to less concentration section. The activation energy has many advantages in chemical engineering industry, food processing, mechanics of water, oil emulsions and geothermal reservoirs, etc. Bestman [30] studied the flow using naturally convected binary mixture in a permeable medium along with activation energy. Makinde et al. [31] reported the flow of natural convection with the impacts of reaction, for order $\mathrm{n}$ and activation energy through numerical computations. Maleque [32] examined, with the aid of activation energy, the reactions of exothermic or endothermic on variant convective flows. Hongchun et al. [33] presented meshless barycentric interpolation collocation technique for finding the solution of PDEs which are encountered in many physical problems. Zhang et al. [34] presented numerical technique for fraction control problems using Chebyshev polynomials. Yao et al. [35] developed a mathematical model for investigating the loss of root stone due water flow in dam structure. Hemeda et al. [36] proposed an iterative technique along with integral iterative scheme for linear and nonlinear Fokker-Planck equations. Awad et al. [37] used the time dependent rotating binary fluid flow over a suddenly stretched sheet using the enhanced Arrhenius function. Abbas et al. [38] also studied flow of Casson nanofluid in the locality of stagnation point by using dual chemical reaction and activation energy effects. They modeled mathematically the flow system using spectralcollocation quasi-linearization method. Shafique et al. [39] used numerical approach and give the idea of rotating viscoelastic flow having species of chemically reaction with activation energy.

The novel contributions of the study are presented as follows:

(i) A novel investigation is presented for modeling and analyzing numerically by shooting method for the three-dimensional Eyring-Powell fluid system with activation energy over a stretching sheet arising in the field of fluid dynamics

(ii) The strength of similarity transformation is exploited to transform the nonlinear PDEs of fluidic model into system of nonlinear ODEs.

(iii) The proposed results are compared with the stateof-the-art counterpart to prove its effectiveness and correctness.

(iv) Numerical and graphical illustrations are utilized to ascertain the value of the scheme by visualizing and analyzing the performance of proficient physical quantities on velocity, temperature, and concentration profiles of the system.

The rest of the paper is organized as follows: mathematical formulations of the problem are described in Section 2; in 


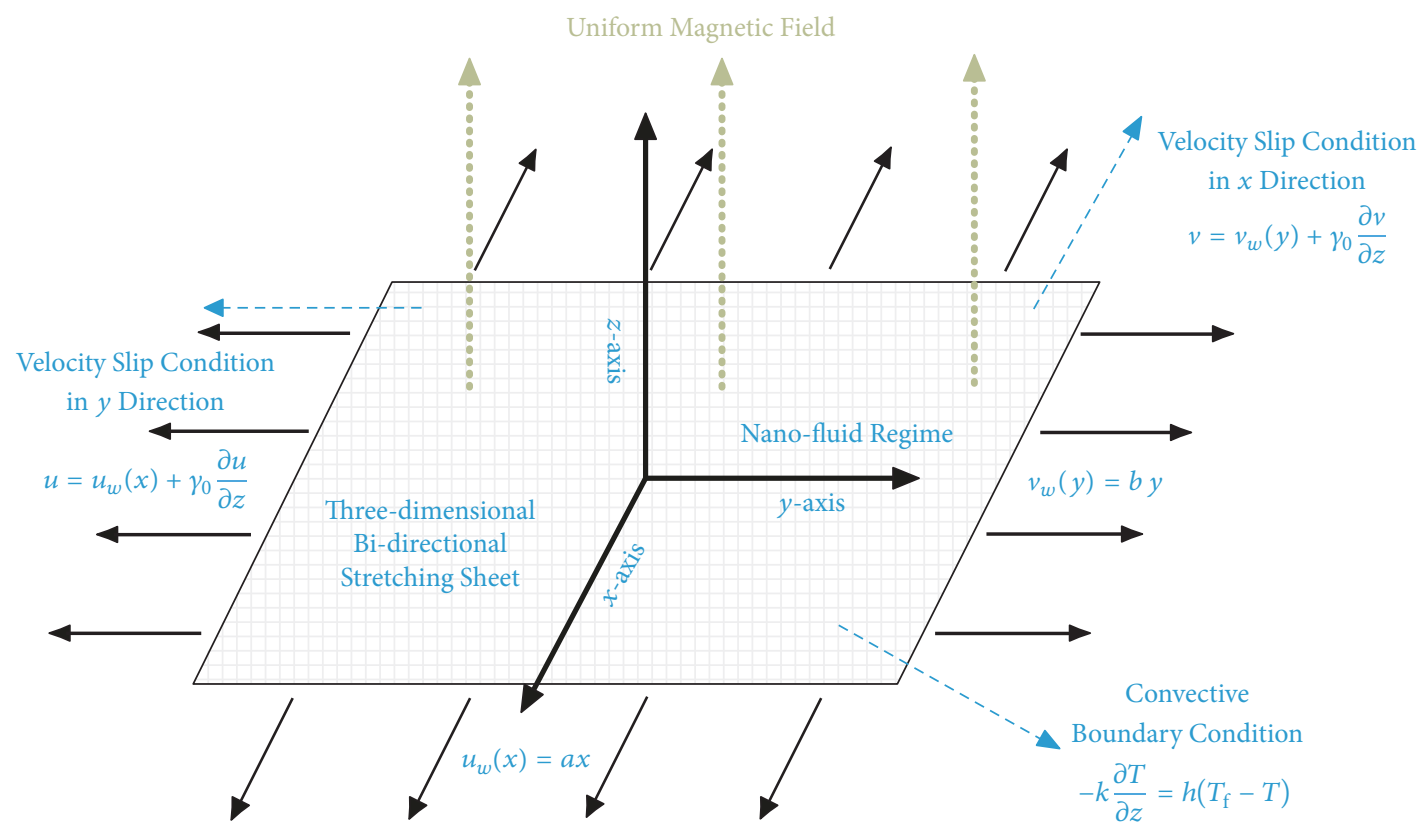

FIGURE 1: Geometrical representation of the problem.

Section 3, results of numerical experiments are provided, while the conclusion along with future research studies is provided in the last section.

In the current investigation, the three-dimensional Eyring-Powell fluid flow near a stretching surface with velocity slip and activation energy is discussed. To discover the full insight of the behavior of different parameters on velocities, energy, and concentration utilities, a well-known shooting technique along with fourth-order Runge-Kutta technique has been employed.

\section{Mathematical Formulation}

In this section, the detailed mathematical analysis for time independent incompressible three-dimensional EyringPowell fluid boundary layer flow, in the presence of activation energy, has been investigated. The region $z>0$ that occupies the flow domain is considered. The sheet is extended in two directions with fixed origin. The velocities of the sheet are $u_{w} x=a x$ and $v_{w} y=b y$ along the longitudinal and transverse directions. Coordinate scale and geometrical interpretation of the problem are exhibited in Figure 1. The velocity component $u$ is along $x$-axis, $v$ is along $y$-axis, and $w$ is along $z$-axis. $C_{w}$ represents nanoparticles concentration at sheet and $C_{\infty}$ is showing the ambient concentration. $T_{f}$ and $T_{\infty}$ are representing the temperature of the convective region and ambient surface. The equations of motions along energy and concentration of the Eyring-Powell model with the effects of activation energy can be expressed as

$$
\left(\frac{\partial u}{\partial x}+\frac{\partial v}{\partial y}+\frac{\partial w}{\partial z}\right)=0
$$

$$
\begin{aligned}
& \left(u \frac{\partial u}{\partial x}+v \frac{\partial u}{\partial y}+w \frac{\partial u}{\partial z}\right) \\
& =\left(v+\frac{1}{\rho \beta_{1} c}\right) \frac{\partial^{2} u}{\partial z^{2}}-\frac{1}{2 \rho \beta_{1} c^{3}}\left(\frac{\partial u}{\partial z}\right)^{2} \frac{\partial^{2} u}{\partial z^{2}}-\frac{\sigma B^{2}}{\rho} u \\
& \left(u \frac{\partial v}{\partial x}+v \frac{\partial v}{\partial y}+w \frac{\partial v}{\partial z}\right) \\
& =\left(v+\frac{1}{\rho \beta_{1} c}\right) \frac{\partial^{2} v}{\partial z^{2}}-\frac{1}{2 \rho \beta_{1} c^{3}}\left(\frac{\partial v}{\partial z}\right)^{2} \frac{\partial^{2} v}{\partial z^{2}}-\frac{\sigma B^{2}}{\rho} v \\
& \left(u \frac{\partial T}{\partial x}+v \frac{\partial T}{\partial y}+w \frac{\partial T}{\partial z}\right) \\
& =\alpha \frac{\partial^{2} T}{\partial z^{2}}+\tau\left\{D_{B} \frac{\partial C}{\partial z} \frac{\partial T}{\partial z}+\frac{D_{T}}{T_{\infty}}\left(\frac{\partial T}{\partial z}\right)^{2}\right\} \\
& \left(u \frac{\partial C}{\partial x}+v \frac{\partial C}{\partial y}+w \frac{\partial C}{\partial z}\right) \\
& =D_{B}\left(\frac{\partial^{2} C}{\partial z^{2}}\right)+\frac{D_{T}}{T_{\infty}}\left(\frac{\partial^{2} T}{\partial z^{2}}\right) \\
& \quad-K r^{2}\left(C-C_{\infty}\right)\left(\frac{T}{T_{\infty}}\right)^{n} \exp \left(\frac{-E_{a}}{k_{1} T}\right)
\end{aligned}
$$

The boundary conditions of the above-mentioned problem are defined as

$$
\begin{aligned}
& u=u_{w}(x)+\gamma_{0} \frac{\partial u}{\partial z} \\
& v=v_{w}(y)+\gamma_{0} \frac{\partial v}{\partial z}
\end{aligned}
$$




$$
\begin{aligned}
& \mathrm{w}=0, \\
& \mathrm{C}=\mathrm{C}_{\mathrm{w}}
\end{aligned}
$$$$
\text { at } z=0,-k \frac{\partial T}{\partial z}=\mathrm{h}\left(\mathrm{T}_{\mathrm{f}}-\mathrm{T}\right)
$$

$$
\begin{aligned}
& u \longrightarrow 0, \\
& v \longrightarrow 0, \\
& T \longrightarrow T_{\infty} \\
& C \longrightarrow C_{\infty}
\end{aligned}
$$

as $z \longrightarrow \infty$.

(6)

We define the below similarity transforms:

$$
\begin{aligned}
\eta & =\sqrt{\frac{a}{v} z^{2}}, \\
u & =a x f^{\prime}(\eta), \\
v & =a y g^{\prime}(\eta), \\
w & =-\sqrt{a v}(f(\eta)+g(\eta)), \\
\theta(\eta) & =\frac{T-T_{\infty}}{T_{f}-T_{\infty}}, \\
\phi(\eta) & =\frac{C-C_{\infty}}{C_{w}-C_{\infty}} .
\end{aligned}
$$

By employing similarity transformations, the nondimensional forms of (1)-(5) are transformed as

$$
\begin{aligned}
& \left(1+\varepsilon-\varepsilon f^{\prime \prime}(\eta)\right) f^{\prime \prime \prime}(\eta)+(f(\eta)+g(\eta)) f^{\prime \prime}(\eta) \\
& -M f^{\prime}(\eta)-\left(f^{\prime}(\eta)\right)^{2}=0, \\
& \left(1+\varepsilon-\varepsilon g^{\prime \prime}(\eta)\right) g^{\prime \prime \prime}(\eta)+(f(\eta)+g(\eta)) g^{\prime \prime}(\eta) \\
& \quad-M g^{\prime}(\eta)-\left(g^{\prime}(\eta)\right)^{2}=0, \\
& \theta^{\prime \prime}(\eta)+\operatorname{Pr}(f(\eta)+g(\eta)) \theta^{\prime}(\eta)+N b \theta^{\prime}(\eta) \phi^{\prime}(\eta) \\
& \quad+N t\left(\theta^{\prime}(\eta)\right)^{2}=0, \\
& \phi^{\prime \prime}(\eta)+\operatorname{Le}(f(\eta)+g(\eta)) \phi^{\prime}(\eta)+\frac{N t}{N b} \theta^{\prime \prime}(\eta) \\
& \quad-\operatorname{Le\sigma }(1+\psi \theta)^{n} \exp \left(\frac{-E}{1+\psi \theta}\right) \phi(\eta)=0 .
\end{aligned}
$$

With the help of similarity transformation (6) can be described as

$$
\begin{aligned}
& f(0)=g(0)=0, \\
& f^{\prime}(0)=1+\gamma f^{\prime \prime}(0), \\
& g^{\prime}(0)=\lambda+\gamma g^{\prime \prime}(0), \\
& \theta^{\prime}(0)=-B i(1-\theta(0)), \\
& \phi(0)=1 ; \\
& f^{\prime}(\eta)=0,
\end{aligned}
$$

$$
g^{\prime}(\eta)=0
$$$$
\theta(\eta)=0
$$$$
\phi(\eta)=0
$$

as $\eta \longrightarrow \infty$.

Various unitless parameters arising in the aforementioned equations are given as

$$
\begin{aligned}
& \psi=\frac{T_{w}-T_{\infty}}{T_{\infty}}, \\
& E=\frac{E_{a}}{k_{1} T_{\infty}}, \\
& \operatorname{Pr}=\frac{v}{a} \text {, } \\
& N_{b}=\frac{\tau D_{B}}{v}\left(C_{w}-C_{\infty}\right), \\
& L e=\frac{v}{D_{B}}, \\
& \gamma=\gamma_{0}\left(\frac{\nu}{a}\right)^{-1 / 2}, \\
& B i=\frac{h}{k} \sqrt{\frac{\nu}{a}}, \\
& \lambda=\frac{b}{a} \\
& M=\frac{\sigma B_{0}^{2}}{a \rho}, \\
& \delta=\frac{b^{3} x^{2}}{2 c^{2} v} \\
& \mu=\nu \rho, \\
& N t=\frac{\tau D_{T}}{v T_{\infty}}\left(T_{f}-T_{\infty}\right), \\
& \epsilon=\frac{1}{\mu \beta c} \text {. }
\end{aligned}
$$


The local skin friction coefficients can be defined in $x$ and $y$ directions as

$$
\begin{aligned}
& C_{f x}=\frac{\tau_{w x}}{\rho U_{w}^{2}}, \\
& C_{f y}=\frac{\tau_{w x}}{\rho U_{w}^{2}}
\end{aligned}
$$

Now we can define the skin frictions $\tau_{w x}$ and $\tau_{w y}$ in $x$ and $y$ directions; the thermal and mass heat fluxes are $q_{w}$ and $q_{m}$ defined as follows.

The dimensional local Nusselt number and Sherwood number, respectively, can be interpret in the form as

$$
\begin{aligned}
N u_{x} & =\frac{x q_{w}}{k_{1}\left(T_{w}-T_{\infty}\right)}, \\
S h_{x} & =\frac{x q_{m}}{k_{1}\left(C_{w}-C_{\infty}\right)} \\
\tau_{w y} & =\mu\left(\frac{\partial u}{\partial z}\right)_{z=0}, \\
\tau_{w x} & =\mu\left(\frac{\partial u}{\partial z}\right)_{z=0}, \\
q_{m} & =-D_{B}\left(\frac{\partial C}{\partial z}\right)_{z=0}, \\
q_{w} & =-k\left(\frac{\partial u}{\partial z}\right)_{z=0} .
\end{aligned}
$$

Using (14) to (16), one can easily get

$$
\begin{aligned}
C_{f x} \operatorname{Re}_{x}^{0.5} & =-f^{\prime \prime}(0) \\
C_{f y} \operatorname{Re}_{x}^{0.5} & =-g^{\prime \prime}(0), \\
\frac{N u_{x}}{\operatorname{Re}_{x}^{0.5}} & =-\theta^{\prime}(0), \\
\frac{S h_{x}}{\operatorname{Re}_{x}^{0.5}} & =-\phi^{\prime}(0) .
\end{aligned}
$$

Here $R e_{x}=u_{w} x / v$ is the Reynolds number which is relied upon on the stretching velocity.

\section{Solution Methodology}

The solutions for coupled nonlinear ODEs (8)-(11) with the aid of boundary conditions (12) are determined by employing the famous shooting method. For the determination of numerical solution, the domain of the problem has been taken as $[0,8]$ instead of $[0, \infty]$. It is observed that the solution for $\eta>8$ has disregarded variations. The initial value problem is obtained from the above boundary value problems. A system of initial value problem has been transformed, in which $f$ by $y_{1}, g$ by $y_{4}, \theta$ by $y_{7}$, and $\phi$ by $y_{9}$ have been used. The resulting equations are written as

$$
\begin{aligned}
& y_{1}^{\prime}=y_{2}, \quad y_{1}(0)=0 \\
& y_{2}^{\prime}=y_{3}, \quad y_{2}(0)=1+\gamma y_{3}(0) \\
& y_{3}^{\prime}=\frac{1}{\left(1+\varepsilon-\varepsilon \delta y_{2}^{2}\right)}\left(-y_{1} y_{3}-y_{3} y_{4}+y_{2}^{2}+M y_{2}\right), \\
& y_{3}(0)=m_{1} \\
& y_{4}^{\prime}=y_{5}, \quad y_{4}(0)=0 \\
& y_{5}^{\prime}=y_{6}, \quad y_{5}(0)=\lambda+\gamma y_{6}(0) \\
& y_{3}^{\prime}=\frac{1}{\left(1+\varepsilon-\varepsilon \delta y_{6}^{2}\right)}\left(-y_{1} y_{6}-y_{4} y_{6}+y_{5}^{2}+M y_{5}\right), \\
& y_{3}(0)=m_{2} \\
& y_{7}^{\prime}=y_{8}, \quad y_{7}(0)=m_{3} \\
& y_{8}^{\prime}=-\left(y_{1}+y_{4}\right) \operatorname{Pr} y_{8}-N b y_{8} y_{10}-N t y_{8}^{2}, \\
& y_{8}(0)=-B i\left(1-y_{7}(0)\right) \\
& y_{9}^{\prime}=y_{10}, \quad y_{9}(0)=1 \\
& y_{10}^{\prime}=-L e\left(y_{1}+y_{4}\right) y_{10}-\frac{N t}{N b} y_{8}^{\prime} \\
& +\operatorname{Le\sigma }\left(1+\psi y_{7}\right) \exp \left(\frac{-E}{1+\psi y_{7}}\right) y_{9} .
\end{aligned}
$$

$$
y_{10}(0)=m_{4}
$$

where $m_{1}, m_{2}, m_{3}$, and $m_{4}$ are the missing initial conditions. To update the initial conditions, Newton's method has been used. The stopping conditions of the iterative process have been set as

$$
\begin{aligned}
& \max \left\{\left|y_{3}\left(\eta_{\text {max }}\right)\right|,\left|y_{6}\left(\eta_{\max }\right)\right|,\left|y_{7}\left(\eta_{\max }\right)\right|,\left|y_{10}\left(\eta_{\max }\right)\right|\right\} \\
& \quad<\xi
\end{aligned}
$$

where $\xi>0$ is a small positive number. In the present study, the numerical outcomes are obtained for $\xi=10^{-6}$

Table 1 shows the deep analysis of presently studied results of $f^{\prime}(0)$ and $g^{\prime}(0)$ against the Hartmann number $M$ and stretching rate ratio parameter $\lambda$ with those of Freidoonimehr et al. [40] and Hayat et al. [41]. The computed results in Table 1 show a very good comparison with the published numerical results. Table 2 shows the comparison of the numerical results of $f^{\prime}(0)$ and $g^{\prime}(0)$ against the stretching rate ratio parameter $\lambda$ with those of Wang [42] and Freidoonimehr et al. [40]. A fabulous agreement is noticed between the computed results and the published numerical results in Table 2. For further validation and strengthening of proposed solver, the obtained numerical results have been compared with the MATLAB built-in solver bvp4c. 
TABLE 1: Comparative analysis of shooting and bvp $4 \mathrm{c}$ results investigating Freidoonimehr et al. [40] and Hayat et al. [41] for $f^{\prime \prime}(0)$ and $g^{\prime \prime}(0)$ when $\gamma=B i=0$.

\begin{tabular}{lccccccccc}
\hline & & Ref. [33] & Ref. [34] & shooting & bvp4c & Ref. [33] & Ref. [34] & shooting & bvp4c \\
\hline$M$ & $\lambda$ & $-f^{\prime \prime}(0)$ & $-f^{\prime \prime}(0)$ & $-f^{\prime \prime}(0)$ & $-f^{\prime \prime}(0)$ & $-g^{\prime \prime}(0)$ & $-g^{\prime \prime}(0)$ & $-g^{\prime \prime}(0)$ & $-g^{\prime \prime}(0)$ \\
\hline 0 & 0 & 1 & 1 & 1 & 1 & 0 & 0 & 0 & 0 \\
1 & 0 & 1.414213 & 1.414214 & 1.414213 & 1.414213 & 0 & 0 & 0 & 0 \\
0 & 0.5 & 1.093095 & 1.093095 & 1.093105 & 1.093105 & 0.465205 & 0.465205 & 0.465213 & 0.465213 \\
1 & 0.5 & 1.476770 & 1.476771 & 1.476770 & 1.476770 & 0.679809 & 0.679809 & 0.679809 & 0.679809 \\
0 & 1 & 1.173721 & 1.173722 & 1.173723 & 1.173723 & 1.173721 & 1.173722 & 1.173723 & 1.173723 \\
1 & 1 & 1.535710 & - & 1.535710 & 1.535710 & 1.535710 & - & 1.535710 & 1.535710 \\
\hline
\end{tabular}

TABLE 2: Comparative analysis of shooting and bvp4c results with those of Wang [42] and Freidoonimehr et al. [40] for $g^{\prime \prime}(0)$ and $f^{\prime \prime}(0)$ when $\gamma=M=0$.

\begin{tabular}{lcccccccc}
\hline & Ref. [35] & Ref. [33] & shooting & bvp4c & Ref. [35] & Ref. [33] & shooting & bvp4c \\
\hline$\lambda$ & $-f^{\prime \prime}(0)$ & $-f^{\prime \prime}(0)$ & $-f^{\prime \prime}(0)$ & $-f^{\prime \prime}(0)$ & $-g^{\prime \prime}(0)$ & $-g^{\prime \prime}(0)$ & $-g^{\prime \prime}(0)$ & $-g^{\prime \prime}(0)$ \\
\hline 0 & 1 & 1 & 1 & 1 & 0 & 0 & 0 \\
0.25 & 1.048813 & 1.048812 & 1.048834 & 1.048834 & 0.194564 & 0.194564 & 0.194576 & 0.194576 \\
0.5 & 1.093097 & 1.093095 & 1.093105 & 1.093105 & 0.465205 & 0.465205 & 0.465213 & 0.465213 \\
0.75 & 1.134485 & 1.134485 & 1.134491 & 1.134491 & 0.794622 & 0.794622 & 0.794623 & 0.794623 \\
1 & 1.173720 & 1.173721 & 1.173723 & 1.173723 & 1.173720 & 1.173720 & 1.173720 & 1.173720 \\
\hline
\end{tabular}

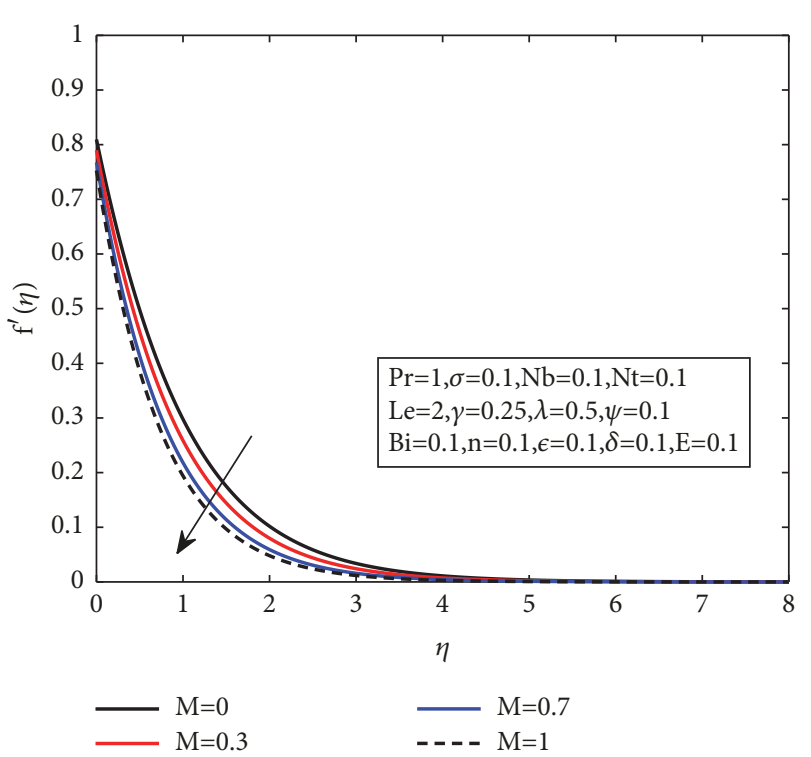

Figure 2: Behavior of $M$ on $f^{\prime}$.

\section{Analysis of Numerical Results}

Figures 2-5 demonstrate the behavior of the velocity components $f^{\prime}$ and $g^{\prime}$, temperature profile $\theta$, and concentration distribution $\phi$ against the Hartmann number $M$. The drag force famous as Lorentz force is obtained by executing the magnetic field vertically through electrically conducting fluid. It is the capability of Lorentz force to make the flow slow which is passing through stretching sheet. With the enhancement in Hartmann number $M$, velocity profile reduces in the directions of $x$ and $y$. As stated above, the

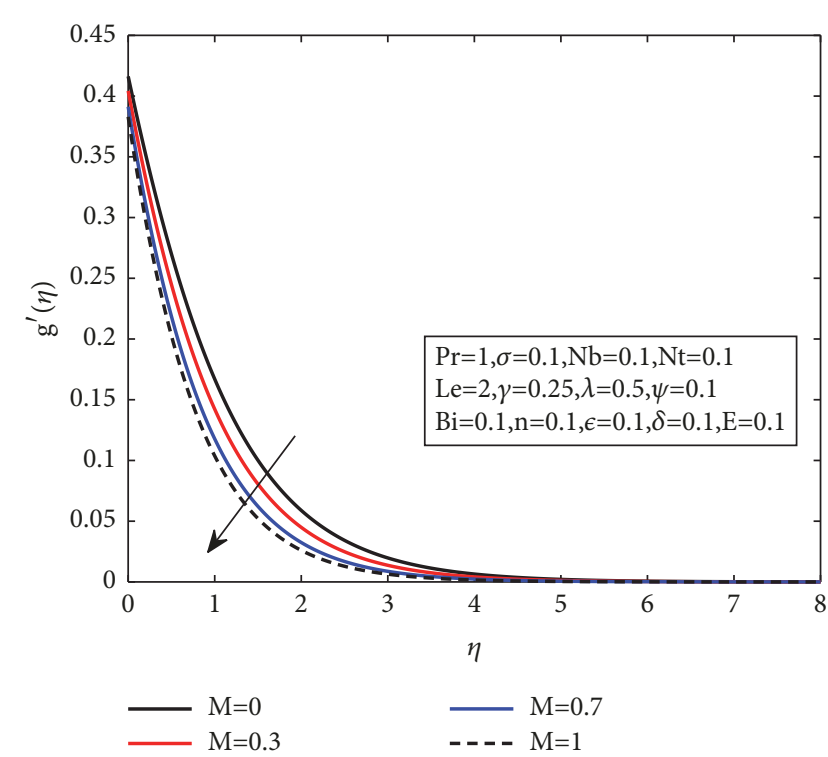

Figure 3: Behavior of $M$ on $g^{\prime}$.

magnetic parameter relies upon the Lorentz force which provides resistance to the flow. By enhancing the Hartmann number, the well-known Lorentz force increases, due to this reason decline in all the component of velocity is observed in the fluid. Moreover, along with this behavior, a small enhancement is observed in the temperature along with concentration distribution by rising the magnetic number $M$. This demonstrates that it is very clear that the transport phenomena are opposed by the transverse magnetic field. It would be significant to describe here that the huge resistances on the fluid elements create heat generation in the flow field, 


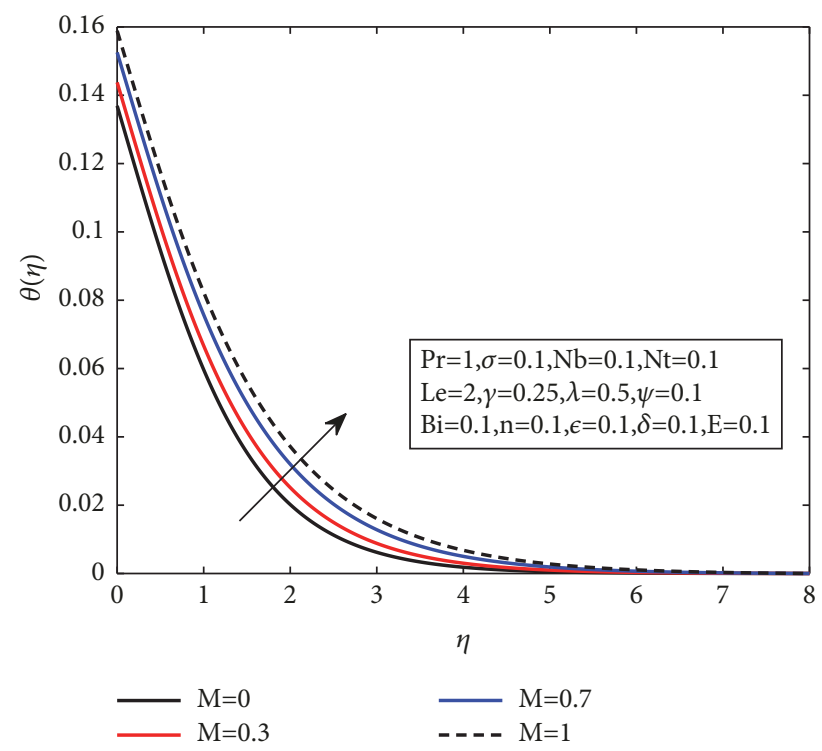

FIgURE 4: Variation of $M$ is investigated on $\theta$.

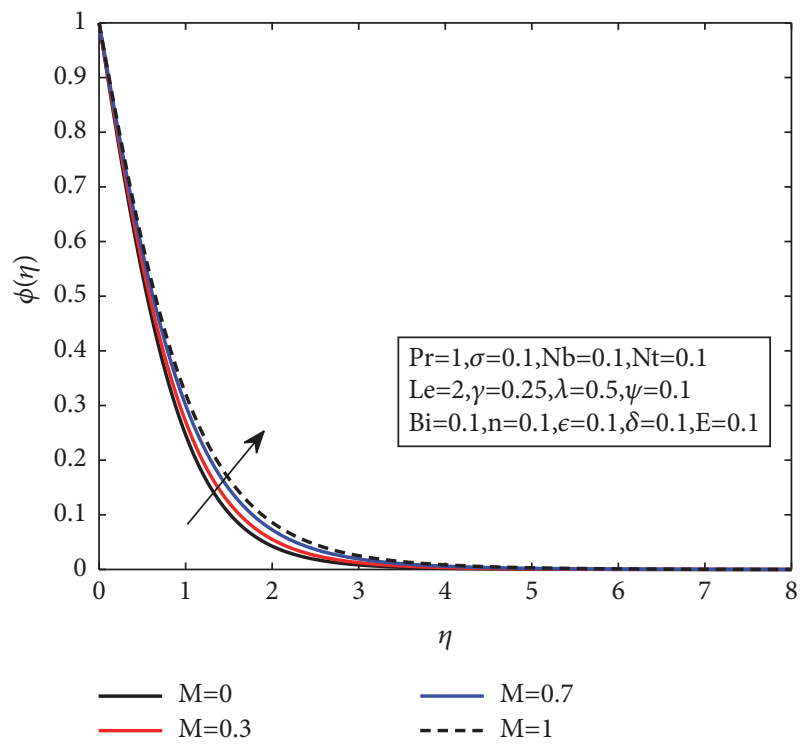

FIgURE 5: Behavior of $M$ on $\phi$.

due to this magnetic field increases vertically. Figures 6-9 narrates the velocity slip parameter $\gamma$ effects on both of the fluid velocity components, temperature, and concentration profiles. Here in this study, the variation of slip parameter is $0<\gamma<1$. By enhancing the values of $\gamma$, decrement is noticed in the fluid velocity components, while the increment is seen in the temperature and concentration profiles. In another sense, the effect of slip becomes stronger, when the smaller quantity of flow is taken outside and it moved ahead in all directions of the flow. By increasing, $\gamma=0$ creates a decline in the saturation of the fixed surface due to the boundary layer in both the axial and transverse directions, which results in decline in the boundary layer thickness of momentum, as reduction in the flow is observed with

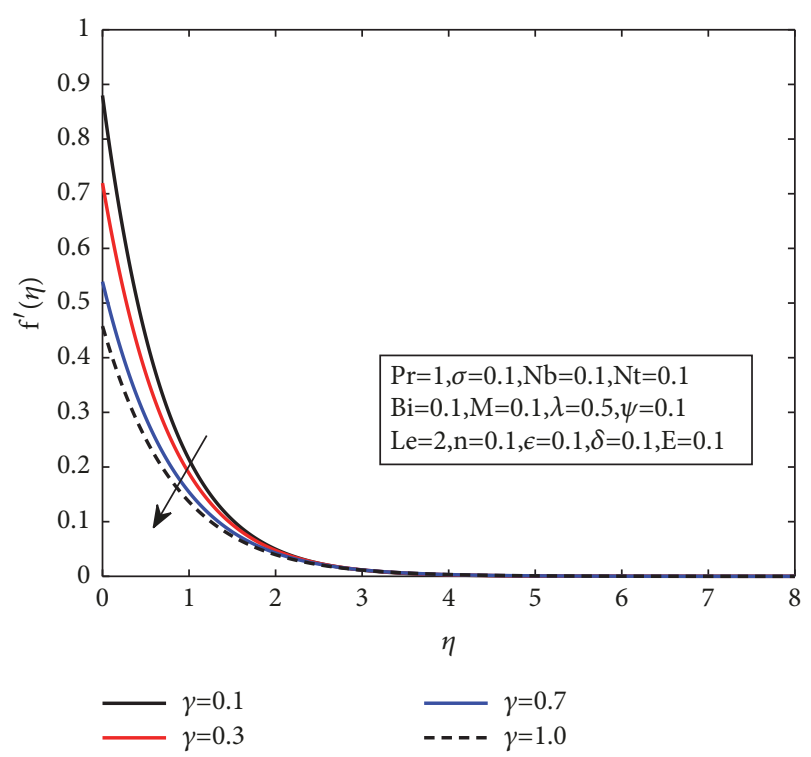

Figure 6: Analysis of $\gamma$ on $f^{\prime}$.

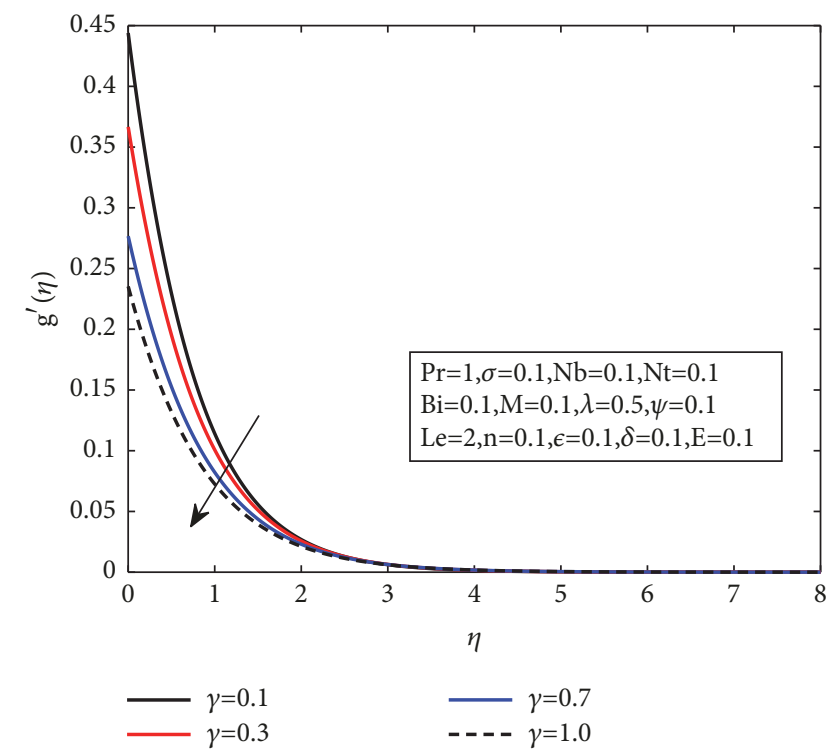

Figure 7: Analysis of $\gamma$ on $g^{\prime}$.

the enhancement in slip so that the skin friction is further decreased from the wall. As described earlier, like behavior is viewed for temperature profile along with slip effect for the nanoparticle concentration field. The effects stretching parameter $\lambda$ on the different components of fluid velocity, profiles of temperature, and concentration are demonstrated in Figures 10-13. By the definition of stretching parameter, when $\lambda=0$ shows the case of nonbidirectional stretching sheet, due to this fact, $g^{\prime}$ tend to zero and improvement in the two-dimensional case is achieved. Moreover, in the case of $\lambda=1$, the stretching parameter becomes similar in the axial and transverse directions. It is worth mentioning here that, by increasing, $\lambda$ signifies the sheet velocity in $y$ direction; that is, $g^{\prime}$ increases; or decrements are noticed in $x$ direction, that is, 


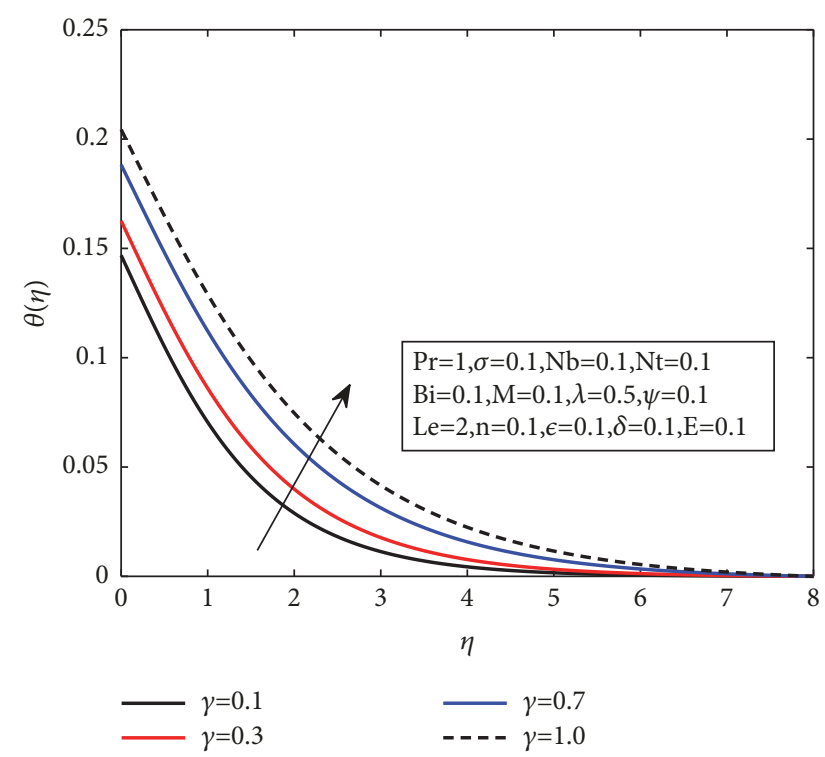

Figure 8: Demonstrates the impact of $\gamma$ on temperature profile.

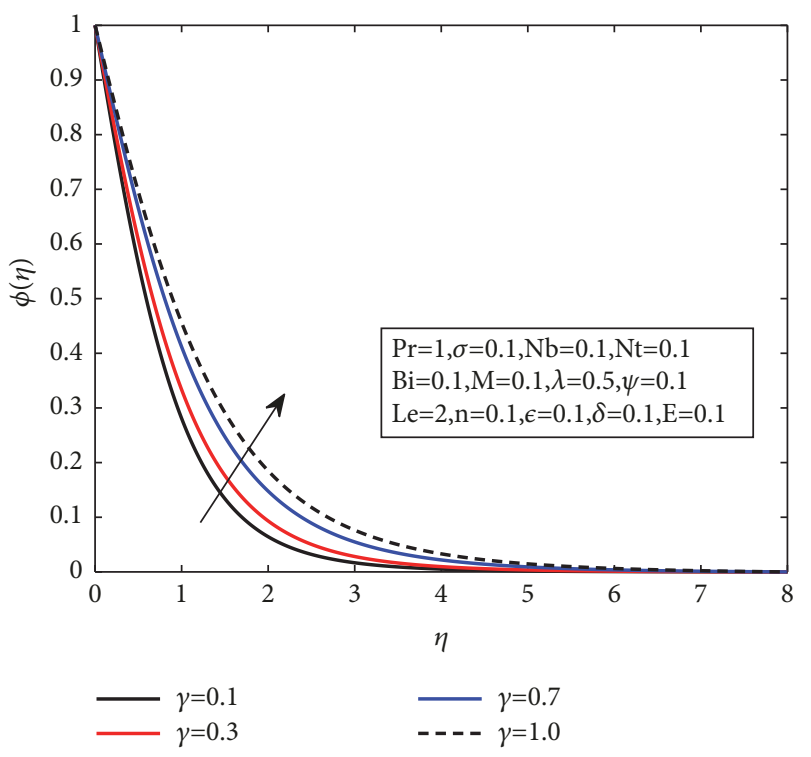

FIgURE 9: Impact of $\gamma$ on $\phi$.

$f^{\prime}$. Generally, as $\lambda$ enhances from zero, then the lateral surface moves in the $y$ direction. In addition to this, increasing in the values of $\lambda$ and decreases in the thermal boundary layer thickness are viewed, because boundary layer thickness and concentration profile are reduced. Figures 14 and 15 illustrate the impacts of the Biot number $B i$ on the temperature profile and concentration fields. The fixed wall temperature $\theta(0)=1$ is attained by taking higher values of the Biot number. The heat transfer coefficient increases by enhancing the values of the Biot number. Rise in the heat transfer coefficient enhances the temperature profile. Moreover, the concentration profile that is driven by temperature profile increases by increases in the Biot number. The dynamic of concentration profile verses Lewis number Le parameter is represented

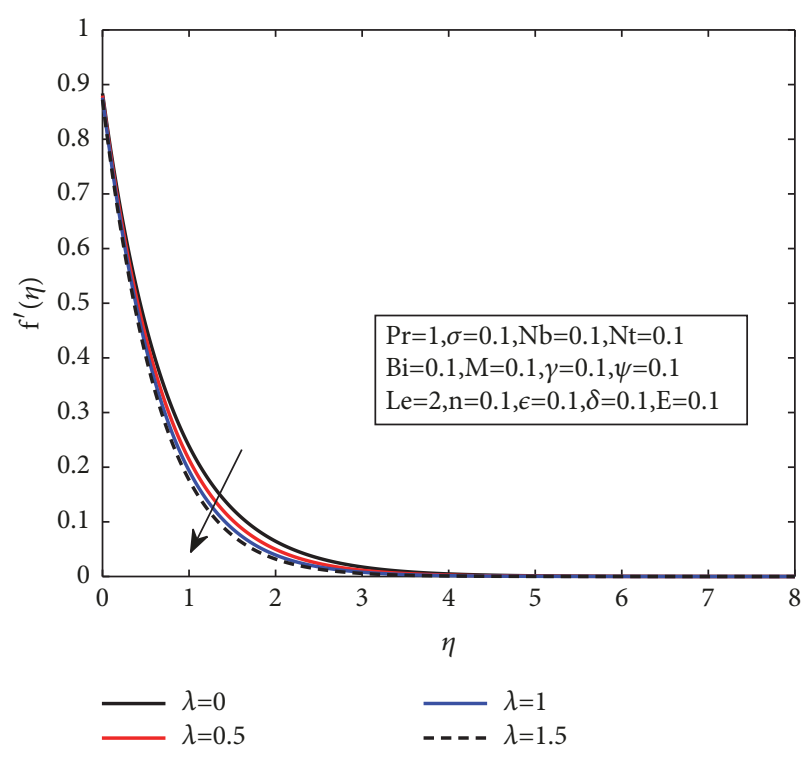

Figure 10: Analysis of $\lambda$ on $f^{\prime}$.

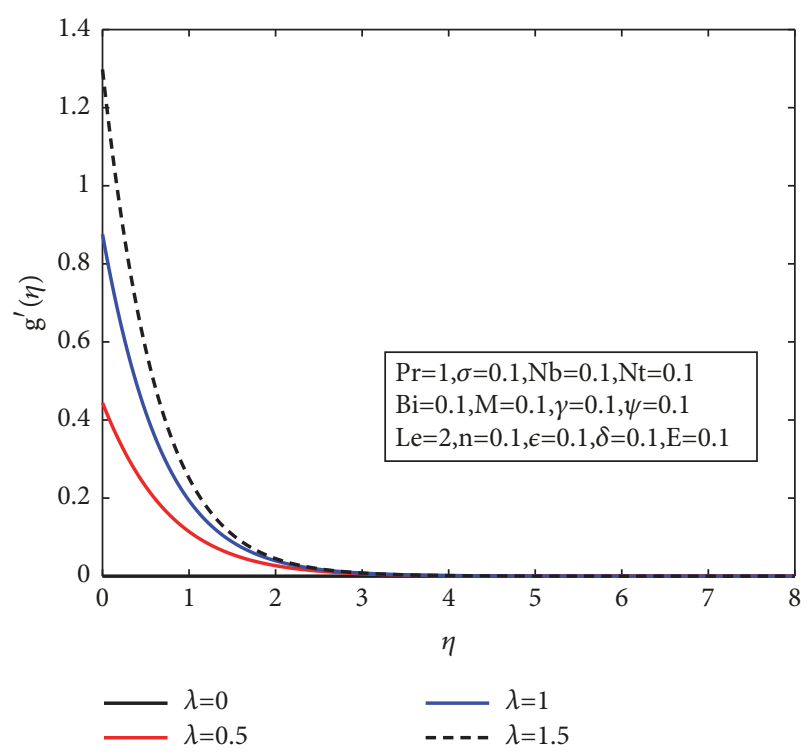

FIGURE 11: Demonstrates the impact of $\lambda$ on $g^{\prime}$.

in Figure 16. In boundary layer, region Le represents the comparative contribution of the rate of thermal diffusion to the species diffusion. Lewis number is increased due to the species boundary layer decline and the concentration distribution tends to zero. The behavior of the temperature profile against thermophoresis parameter is presented in Figure 17. It is noticed that if thermophoresis parameter $\mathrm{Nt}$ is increased, enhancement in the thermal and concentration boundary layer thicknesses is achieved. The reason is behind the fact that submersion of the nanoparticles improves the thermal conductivity of the fluid; due to this an increment is seen in the temperature profile. This is quite evident from Figure 18 that, by increasing the dimensionless activation energy $E$, increment is seen in the nanoparticle concentration 


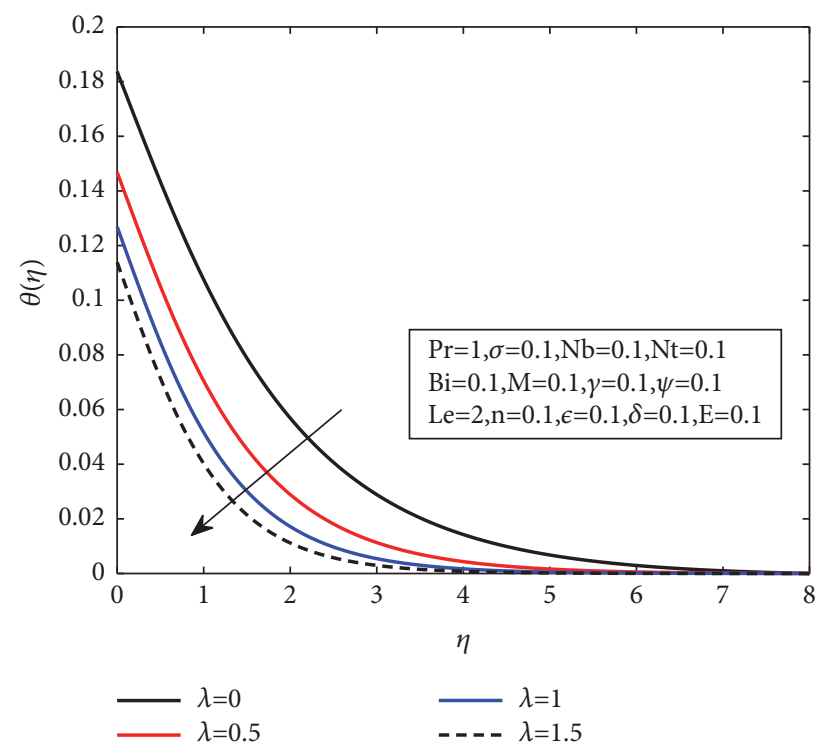

FIgURE 12: Behavior of $\lambda$ on $\theta$.

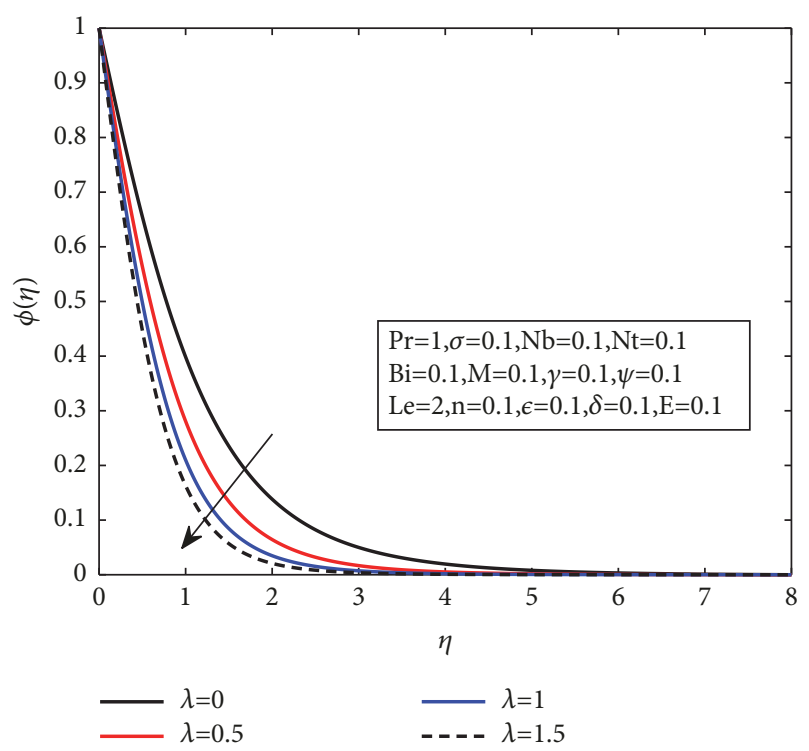

Figure 13: Effect of $\lambda$ on $\phi$.

profile. The reason behind this fact is Arrhenius function. This function reduces when the activation energy increases, leading to start the generative chemical reaction. Figure 19 portrays the reaction rate constant $\sigma$ versus mass fraction field $\phi$. It shows that, by increasing $\sigma$ results, the mass fraction field $\phi$ reduces. The reason behind this fact is the presence of the huge concentration gradient at the boundary wall.

\section{Conclusion}

A new numerical approach based on shooting method is designed effectively for the problem arising in the field of fluid dynamics represented with the three-dimensional

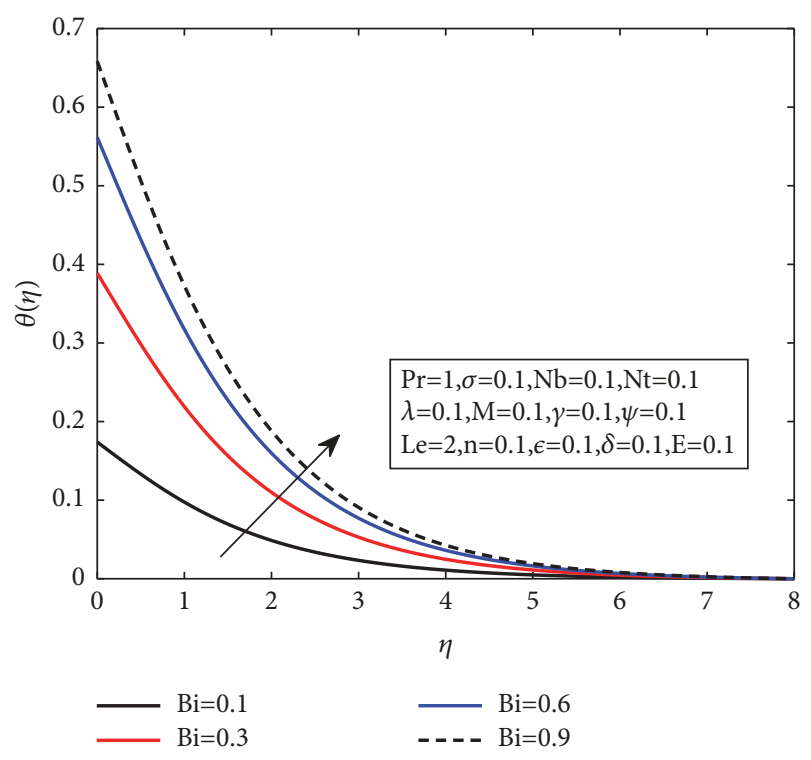

Figure 14: Analysis of $B i$ on $\theta$.

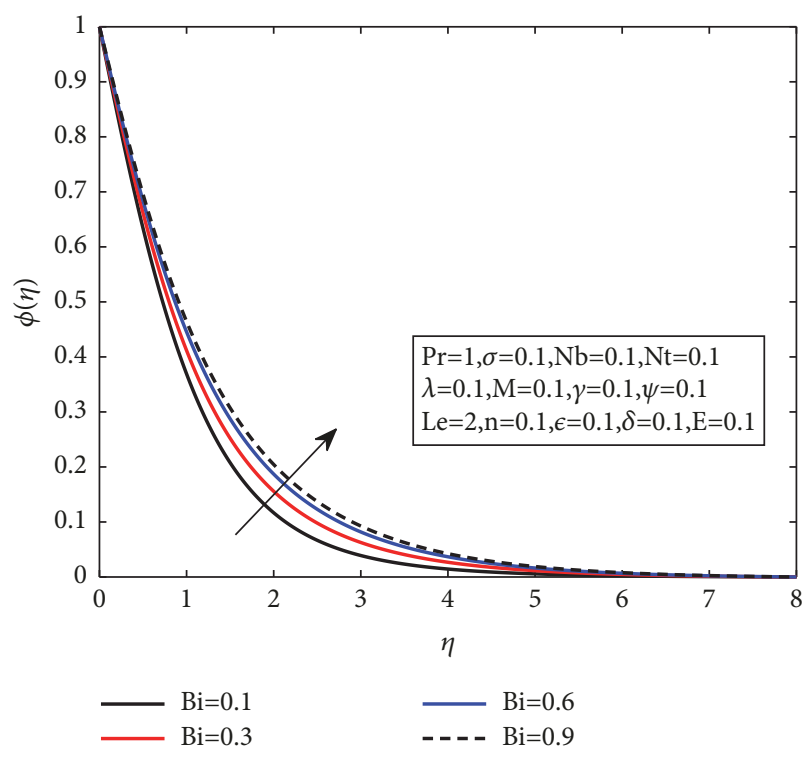

FIGURE 15: The impact of $B i$ on $\phi$.

non-Newtonian Eyring-Powell fluid flow near a stretching surface along with the variations of velocity slip and the Arrhenius activation energy. The potential key inferences are summarized as follows:

(i) The strength of the proposed solver has been proved by comparing with the results of state of art solver bvp4c

(ii) By increasing the Hartmann number and velocity slip parameter, the velocity profile of the fluid declines, while increment is observed in the temperature distribution and concentration profile. 


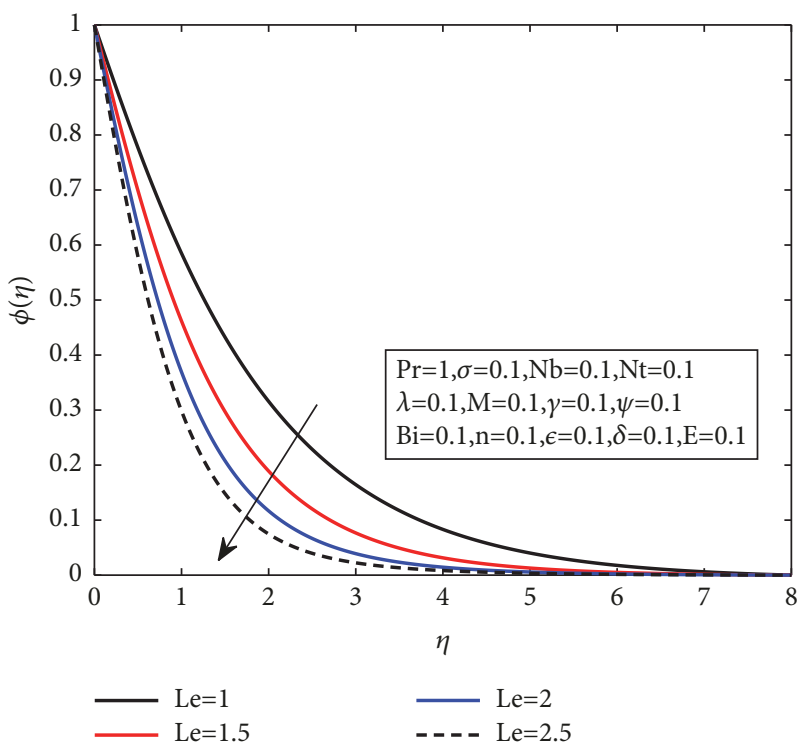

Figure 16: The impact of Le on $\phi$.

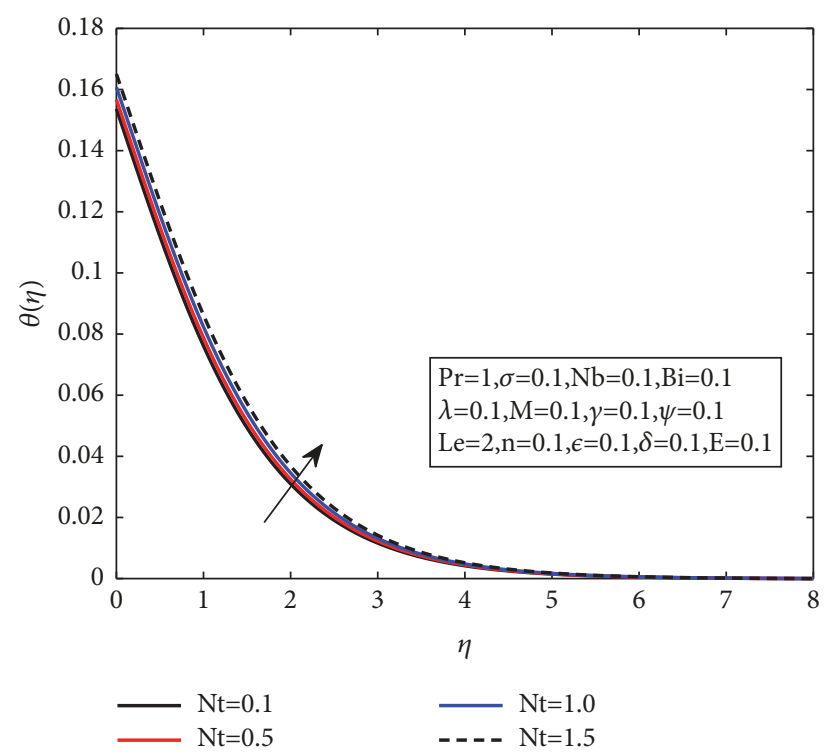

FIGURE 17: Behavior of $N t$ on $\theta$.

(iii) The activation energy strength enhances the mass fraction field, where as the wall mass flux declines.

(iv) Rise in the temperature and concentration profiles is witnessed with the increase of Biot number.

In future one may investigate stochastic numerical paradigm based on evolutionary and swarming optimized spline method for the superior numerical treatment of given fluidic system

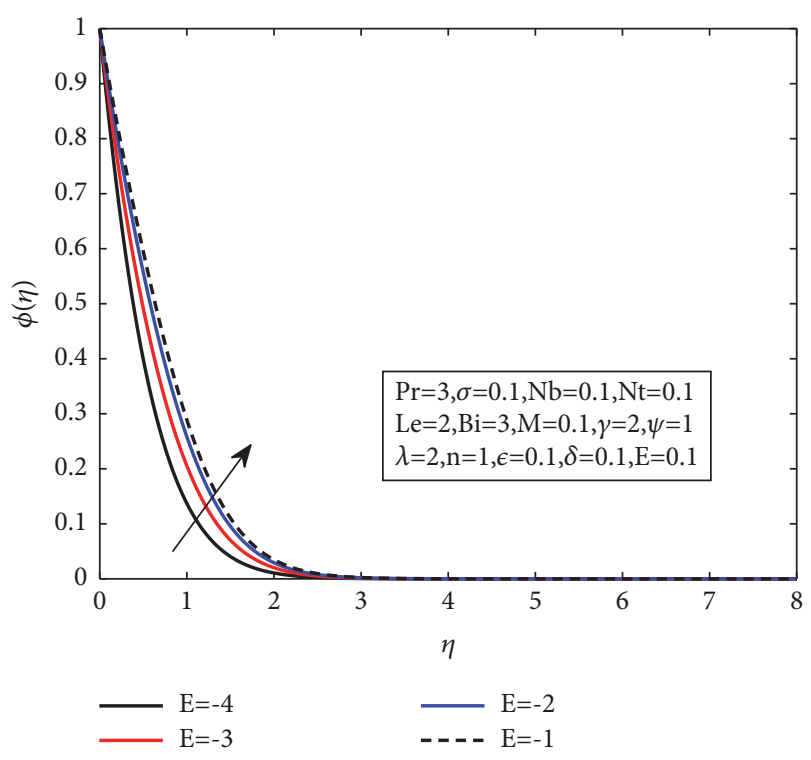

Figure 18: Behavior of $E$ on $\phi$.

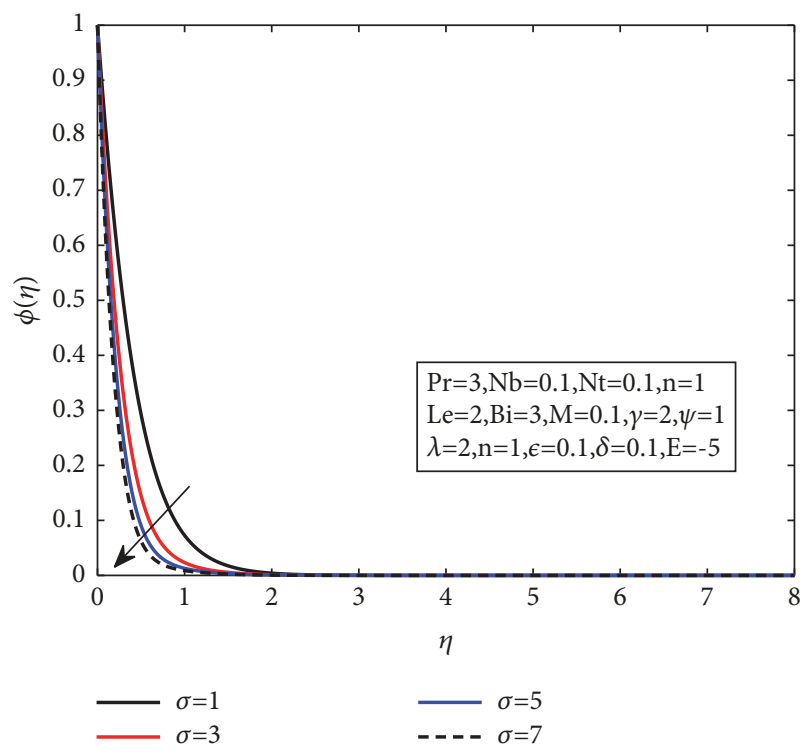

FIGURE 19: Variance of $\sigma$ on $\phi$.

\section{Nomenclature}

$B_{0}$ : Constant magnetic field

$\beta$ : $\quad$ Material parameter

$B i$ : Biot number

$M$ : Magnetic number

Le: Lewis number

$N b$ : Brownian motion parameter

Nt: Thermophoresis parameter

$C$ : Nanoparticle concentration

$C_{w}$ : Concentration of nanoparticle

Pr: Prandtl number

$C_{\infty}$ : Ambient concentration 


$\begin{array}{ll}C_{f}: & \text { Friction coefficient } \\ R: & \text { Auxiliary function } \\ D: & \text { Coefficient of Brownian diffusion } \\ R e: & \text { Reynolds number } \\ D_{T}: & \text { Coefficient of thermophoretic diffusion } \\ \nu: & \text { Kinematic viscosity } \\ N b: & \text { Brownian motion factor } \\ E: & \text { Activation energy } \\ K: & \text { Material parameter } \\ N t: & \text { Thermophoresis factor } \\ \sigma: & \text { Reaction rate constant } \\ n: & \text { Fitted rate constant } \\ f(\eta), g(\eta): & \text { Velocity similarity functions } \\ T: & \text { Temperature } \\ T_{f}: & \text { Convective surface temperature } \\ T_{\infty}: & \text { Ambient temperature } \\ u, v, w: & \text { Components of velocity } \\ x, y, z: & \text { Cartesian coordinates } \\ N t: & \text { Thermophoresis factor } \\ \alpha: & \text { Thermal diffusivity } \\ \gamma: & \text { Slip parameter } \\ \gamma_{0}: & \text { Slip length } \\ \eta: & \text { Similarity parameter } \\ \theta(\eta): & \text { Temperature distribution } \\ \lambda: & \text { Stretching parameter } \\ \rho: & \text { Fluid density } \\ \kappa: & \text { Thermal conductivity } \\ \varepsilon, \delta: & \text { Nondimensional fluid parameter } \\ \phi(\eta): & \text { Concentration. } \\ & \end{array}$

\section{Data Availability}

All the data used in this research work is available within the manuscript.

\section{Conflicts of Interest}

The authors declare that they have no conflicts of interest.

\section{References}

[1] R. E. Powell and H. Eyring, "Mechanisms for the relaxation theory of viscosity," Nature, vol. 154, no. 3909, pp. 427-428, 1944.

[2] M. Patel and M. G. Timol, "Numerical treatment of PowellEyring fluid flow using method of satisfaction of asymptotic boundary conditions (MSABC)," Applied Numerical Mathematics, vol. 59, no. 10, pp. 2584-2592, 2009.

[3] V. Sirohi, M. G. Timol, and N. L. Kalthia, "Powell-Eyring model flow near an accelerated plate," Fluid Dynamics Research, vol. 2, no. 3, pp. 193-204, 1987.

[4] H. K. Yoon and A. J. Ghajar, "A note on the Powell-Eyring fluid model," International Communications in Heat and Mass Transfer, vol. 14, no. 4, pp. 381-390, 1987.

[5] S. Nadeem, N. S. Akbar, and M. Ali, "Endoscopic effects on the peristaltic flow of an Eyring-Powell fluid," Meccanica, vol. 47, no. 3, pp. 687-697, 2012.

[6] T. M. Agbaje, S. Mondal, S. S. Motsa, and P. Sibanda, "A numerical study of unsteady non-Newtonian Powell-Eyring nanofluid flow over a shrinking sheet with heat generation and thermal radiation," Alexandria Engineering Journal, vol. 56, no. 1, pp. 81-91, 2017.

[7] M. J. Babu, N. Sandeep, and C. S. K. Raju, "Heat and mass transfer in MHD eyring-powell nanofluid flow due to cone in porous medium," International Journal of Engineering Research in Africa, vol. 19, p. 57, 2015.

[8] T. Hayat, M. Zubair, M. Waqas, A. Alsaedi, and M. Ayub, "On doubly stratified chemically reactive flow of Powell-Eyring liquid subject to non-Fourier heat flux theory," Results in Physics, vol. 7, pp. 99-106, 2017.

[9] M. Mustafa, T. Hayat, I. Pop, S. Asghar, and S. Obaidat, "Stagnation-point flow of a nanofluid towards a stretching sheet," International Journal of Heat and Mass Transfer, vol. 54, no. 25-26, pp. 5588-5594, 2011.

[10] O. D. Makinde and A. Aziz, "Boundary layer flow of a nanofluid past a stretching sheet with a convective boundary condition," International Journal of Thermal Sciences, vol. 50, no. 7, pp. 13261332, 2011.

[11] M. Sheikholeslami and D. D. Ganji, "Heat transfer of Cu-water nanofluid flow between parallel plates," Powder Technology, vol. 235, pp. 873-879, 2013.

[12] M. Goodarzi, M. Safaei, K. Vafai et al., "Investigation of nanofluid mixed convection in a shallow cavity using a twophase mixture model," International Journal of Thermal Sciences, vol. 75, pp. 204-220, 2014.

[13] A. Malvandi and D. D. Ganji, "Mixed convective heat transfer of water/alumina nanofluid inside a vertical microchannel," Powder Technology, vol. 263, pp. 37-44, 2014.

[14] A. V. Kuznetsov and D. A. Nield, "Natural convective boundarylayer flow of a nanofluid past a vertical plate: a revised model," International Journal of Thermal Sciences, vol. 77, pp. 126-129, 2014.

[15] T. Hayat, T. Muhammad, S. A. Shehzad, and A. Alsaedi, "Similarity solution to three dimensional boundary layer flow of second grade nanofluid past a stretching surface with thermal radiation and heat source/sink," AIP Advances, vol. 5, no. 1, Article ID 017107, 2015.

[16] F. Hedayati, A. Malvandi, M. H. Kaffash, and D. D. Ganji, "Fully developed forced convection of alumina/water nanofluid inside microchannels with asymmetric heating," Powder Technology, vol. 269, pp. 520-531, 2015.

[17] T. Hayat, T. Muhammad, S. A. Shehzad, and A. Alsaedi, "Three-dimensional boundary layer flow of Maxwell nanofluid: mathematical model," Applied Mathematics and MechanicsEnglish Edition, vol. 36, no. 6, pp. 747-762, 2015.

[18] R. Ellahi, M. Hassan, and A. Zeeshan, "Shape effects of nanosize particles in $\mathrm{Cu}$ - H $2 \mathrm{O}$ nanofluid on entropy generation," International Journal of Heat and Mass Transfer, vol. 81, pp. 449456, 2015.

[19] N. A. Abdul Latiff, M. J. Uddin, O. A. Bég, and A. I. Ismail, "Unsteady forced bioconvection slip flow of a micropolar nanofluid from a stretching/shrinking sheet," Proceedings of the Institution of Mechanical Engineers, Part N: Journal of Nanomaterials, Nanoengineering and Nanosystems, vol. 230, no. 4, pp. 177-187, 2016.

[20] M. J. Uddin, M. N. Kabir, and O. A. Bég, "Computational investigation of Stefan blowing and multiple-slip effects on buoyancy-driven bioconvection nanofluid flow with microorganisms," International Journal of Heat and Mass Transfer, vol. 95, pp. 116-130, 2016. 
[21] J. Maxwell Clerk, "VII. On stresses in rarified gases arising from inequalities of temperature," Philosophical Transactions of the royal society of London, vol. 170, pp. 231-256, 1879.

[22] Y-T. Hsia and G. A. Domoto, "An experimental investigation of molecular rarefaction effects in gas lubricated bearings at ultralow clearances," Journal of Lubrication Technology, vol. 105, no. 1, pp. 120-129, 1983.

[23] S. Fukui and R. Kaneko, "A database for interpolation of poiseuille flow rates for high knudsen number lubrication problems," Journal of Tribology, vol. 112, no. 1, pp. 78-83, 1990.

[24] Y. Mitsuya, "Modified reynolds equation for ultra-thin film gas lubrication using 1.5-Order slip-flow model and considering surface accommodation coefficient," Journal of Tribology, vol. 115, no. 2, pp. 289-294, 1993.

[25] L. A. Wu, "A slip model for rarefied gas flows at arbitrary Knudsen number," Applied Physics Letters, vol. 93, no. 25, Article ID 253103, 2008.

[26] W. Ibrahim and B. Shankar, "MHD boundary layer flow and heat transfer of a nanofluid past a permeable stretching sheet with velocity, thermal and solutal slip boundary conditions," Computers \& Fluids, vol. 75, pp. 1-10, 2013.

[27] Y. Zhang, J. Niu, and S. Na, "A novel nonlinear function fitting model based on FOA and GRNN," Mathematical Problems in Engineering, vol. 2019, Article ID 2697317, 10 pages, 2019.

[28] X. Duan, H. Ren, and H. Li, "Incompressible fluids simulation by relaxing the density-invariant condition in a marine simulator," Mathematical Problems in Engineering, vol. 2019, Article ID 8971089, 11 pages, 2019.

[29] Q. Mu, Y. Lv, K. Wang, T. Xiong, and W. Yi, "Numerical simulation on the cavitation flow of high speed oblique water entry of revolution body," Mathematical Problems in Engineering, vol. 2019, Article ID 8034619, 10 pages, 2019.

[30] A. R. Bestman, "Natural convection boundary layer with suction and mass transfer in a porous medium," International Journal of Energy Research, vol. 14, no. 4, pp. 389-396, 1990.

[31] O. D. Makinde, P. O. Olanrewaju, and W. M. Charles, "Unsteady convection with chemical reaction and radiative heat transfer past a flat porous plate moving through a binary mixture," Afrika Matematika, vol. 22, no. 1, pp. 65-78, 2011.

[32] K. A. Maleque, "Effects of exothermic/endothermic chemical reactions with Arrhenius activation energy on MHD free convection and mass transfer flow in presence of thermal radiation," Journal of Thermodynamics, vol. 2013, Article ID 692516, 11 pages, 2013.

[33] H. Wu, Y. Wang, and W. Zhang, "Numerical solution of a class of nonlinear partial differential equations by using barycentric interpolation collocation method," Mathematical Problems in Engineering, vol. 2018, Article ID 7260346, 10 pages, 2018.

[34] J. Zhang, Y. Li, and J. Xie, "Numerical simulation of fractional control system using Chebyshev polynomials," Mathematical Problems in Engineering, vol. 2018, Article ID 4270764, 5 pages, 2018.

[35] C. Yao, C. Yang, Y. Lan, Q. Jiang, S. Jiang, and J. Yang, "Numerical simulation study on root stones loss in dam buttress engineering," Mathematical Problems in Engineering, vol. 2018, Article ID 5132760, 15 pages, 2018.

[36] A. A. Hemeda and E. E. Eladdad, "New iterative methods for solving Fokker-Planck equation," Mathematical Problems in Engineering, vol. 2018, Article ID 6462174, 9 pages, 2018.

[37] F. G. Awad, S. Motsa, and M. Khumalo, "Heat and mass transfer in unsteady rotating fluid flow with binary chemical reaction and activation energy," PLOS ONE, vol. 9, no. 9, Article ID e107622, 2014.

[38] Z. Abbas, M. Sheikh, and S. S. Motsa, "Numerical solution of binary chemical reaction on stagnation point flow of Casson fluid over a stretching/shrinking sheet with thermal radiation," Energy, vol. 95, pp. 12-20, 2016.

[39] Z. Shafique, M. Mustafa, and A. Mushtaq, "Boundary layer flow of Maxwell fluid in rotating frame with binary chemical reaction and activation energy," Results in Physics, vol. 6, pp. 627-633, 2016.

[40] N. Freidoonimehr and A. B. Rahimi, "Brownian motion effect on heat transfer of a three-dimensional nanofluid flow over a stretched sheet with velocity slip," Journal of Thermal Analysis and Calorimetry, pp. 1-16, 2018.

[41] T. Hayat, S. A. Shehzad, M. Qasim, and S. Asghar, "Threedimensional stretched flow via convective boundary condition and heat generation/absorption," International Journal of Numerical Methods for Heat \& Fluid Flow, vol. 24, no. 2, pp. 342-358, 2014.

[42] C. Y. Wang, "The three dimensional flow due to a stretching flat surface," Physics of Fluids, vol. 27, no. 8, pp. 1915-1917, 1984. 


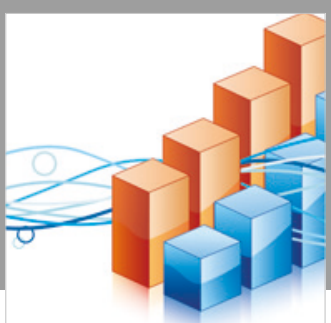

Advances in

Operations Research

\section{-n-m}
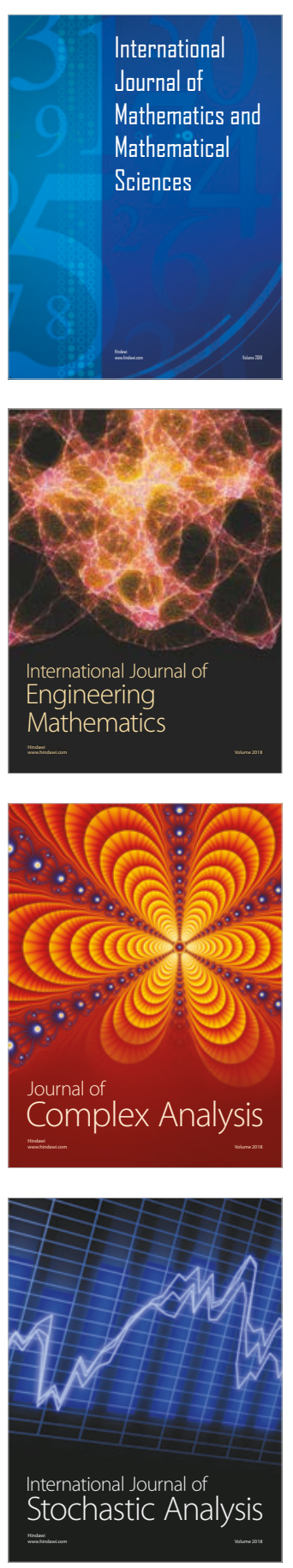
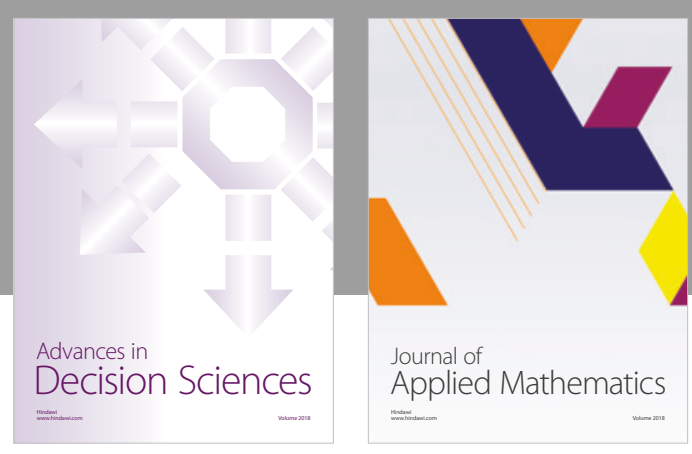

Journal of

Applied Mathematics
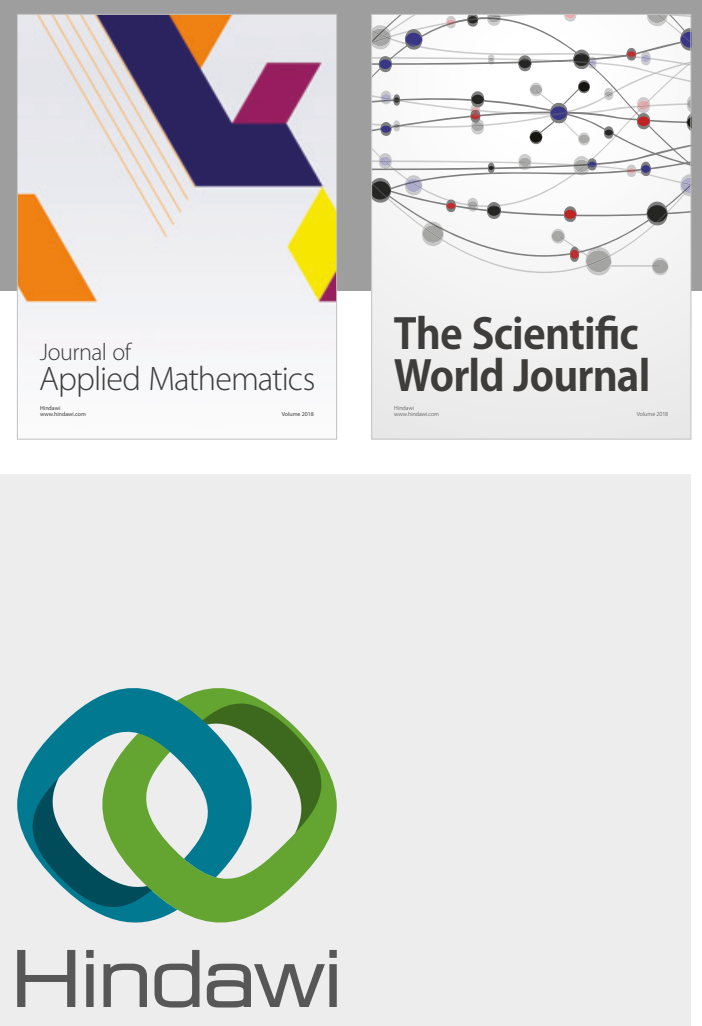

Submit your manuscripts at

www.hindawi.com

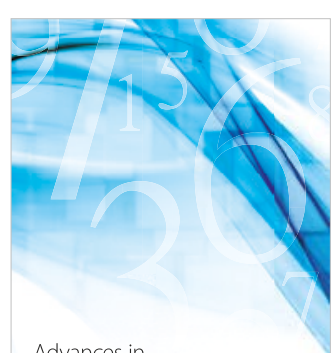

Advances in
Numerical Analysis
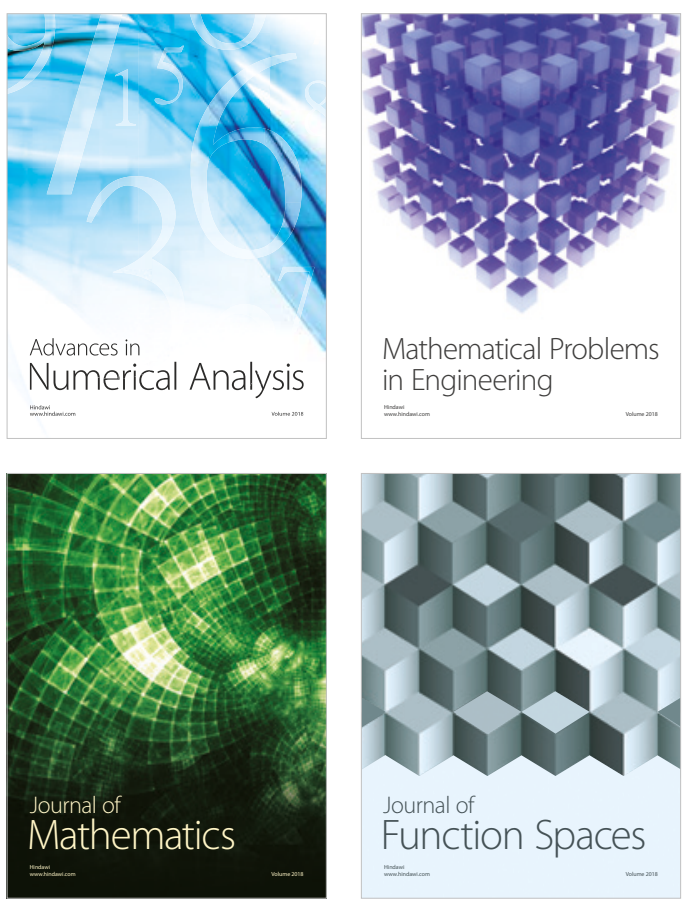

Mathematical Problems in Engineering

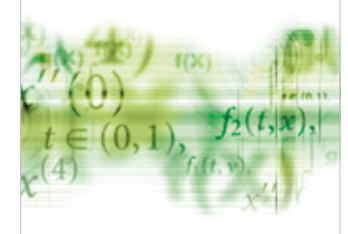

International Journal of

Differential Equations

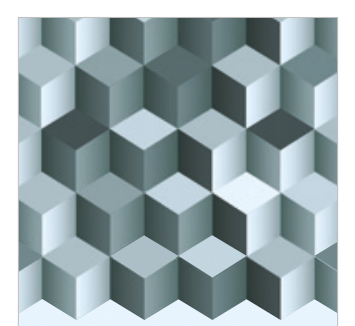

Journal of

Function Spaces

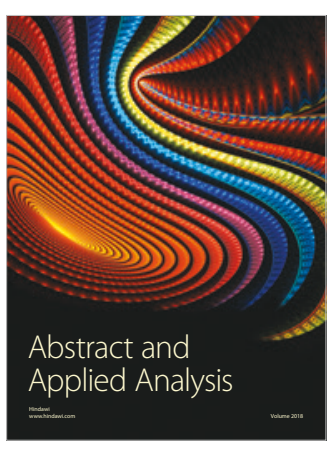

The Scientific

World Journal

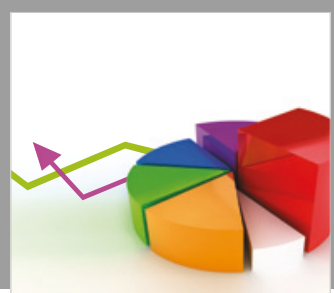

Journal of

Probability and Statistics
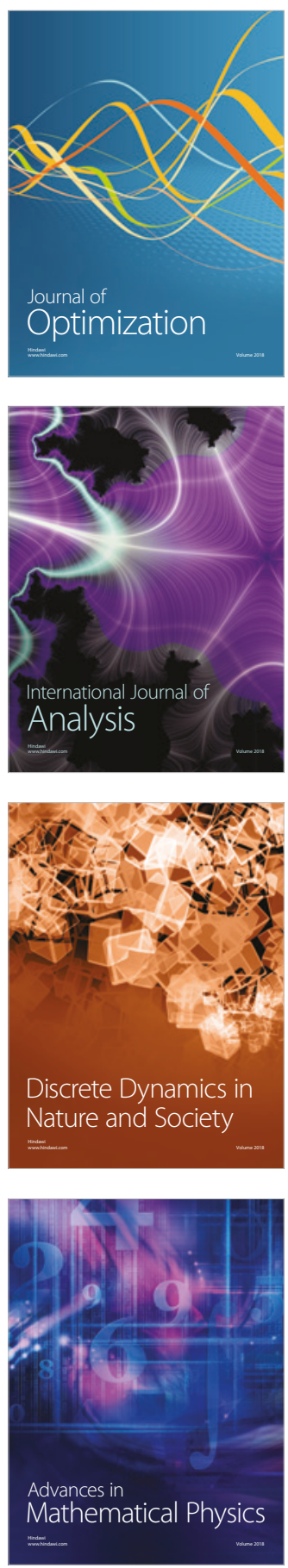